\title{
Bronchospasm, CTCAE
}

National Cancer Institute

\section{Source}

National Cancer Institute. Bronchospasm, CTCAE. NCI Thesaurus. Code C143344.

A disorder characterized by a sudden contraction of the smooth muscles of the bronchial wall. 